\title{
Effect of Availability and Utilization of Physics Laboratory Equipment on Students' Academic Achievement in Senior Secondary School Physics
}

\author{
Bello Theodora Olufunke ${ }^{1, *}$
}

\author{
${ }^{1}$ Institute of Education, Obafemi Awolowo University, Ile-Ife, Nigeria \\ *Correspondence: Bello, Theodora Olufunke, Institute of Education, Faculty of Education, Obafemi Awolowo \\ University, Ile-Ife, Nigeria. Tel.: +234-806-618-5222. E-mail: bledora@yahoo.co.uk or bledore@oauife.edu.ng
}

Received: June 1, 2012

doi:10.5430/wje.v2n5p1
Accepted: August 19, 2012

Online Published: September 18, 2012

\begin{abstract}
The study determined the available Physics Laboratory Equipment (PLE) for the teaching and learning of physics in senior secondary schools in Nigeria as well as the extent of utilizing the available equipment. The research design adopted for the study was descriptive survey. The sample consisted of nine hundred students who were randomly chosen and fifty Physics teachers who were purposively selected from forty five senior secondary schools in the south western region of Nigeria.Three instruments were used for the collection of data for the study. They are a self-designed questionnaire tagged "Physics Laboratory Equipment Questionnaire" (PLEQ) with reliability of 0.72, a checklist of Physics equipment and Physics Achievement Test (PAT) to measure students' achievement. The results showed that the optimal utilization of physics laboratory equipment is effective in the teaching of Physics. The federal schools had the maximum adequately utilized PLE and had the highest mean score,followed by the private schools while the public schools with the minimum available equipment and least utilization capacity had the minimum mean score. The study concluded that science laboratory with adequate equipment is a critical variable in determining the quality of output from senior secondary school Physics.
\end{abstract}

Keywords: Laboratory, Equipment, Physics, Utilization, Achievement

\section{Introduction}

Science had been of great importance internationally for sustainable and socio-economic development as well as for technological advancement of nations. Knowledge of science and technology is therefore a requirement in all countries and needed by all people globally due to numerous challenges that are facing them. These challenges include emergences of new drug resistant diseases, effects of genetic experimentation and engineering, ecological impact of modern technology, dangers of nuclear war and explosions and global warming among others (Alsop \& Hicks, 2001; Minishi, Muni, Okumu, Mutai, Mwangasha, Omolo \& Munyeke, 2004). This had resulted to rapid changes taking place in medicine, industry, communication, and agriculture. Science as an agent of development plays an important role in bringing about these changes through technological advancement, national wealth enhancement, health improvement and industrialization (Validya, 2003), this is why scientific and technological breakthrough is usually the goal of any developing nation like Nigeria. Weham, Dorlin, Snell \& Taylor (1984) opined that Physics is and will remain the fundamental science.

Physics is the bedrock of science and technology because many of the tools on which the scientific and technological advancement depends are the direct products of Physics. Physics is therefore a core subject in science and technology since it studies the essence of natural phenomena and helps people understand the rapidly technological changing society (Zhaoyao, 2002). The principles of Physics has been widely used for various economic, scientific and technological advancement such as in information technology, which has reduced the world into a global village through the use of satellites and computers. Also, the knowledge of Physics had led to sustainable development in the area of industrialisation for improvement of materials useful to the well being of 
human race. Furthermore, Physics education enables the learners to acquire problem-solving and decision-making skills that pave way for critical thinking and inquiry that could help them to respond to widespread and radical changes in all facets of life.

Despite the importance of Physics to the scientific and technological development of our nation, understanding of the subject had dwindled over the years and performance of the enrolled students had not been encouraging. Ho and Boo (2007) discussed that in many countries, there has been a decline in the number of students wishing to continue with physics. Ali (1990), Okebukola (1997), Nneji (1998), Ogunleye (2000) and Umeh (2002) were all of the opinion that students' performances in the science subjects were poor. Also, previous study had shown that students who hold negative stereotype images of scientists, science and technology in society are easily discouraged from pursuing scientific disciplines and usually performed poorly in science subjects (Changeiywo, 2000). This situation does not favour Nigeria's move towards developing a scientific and technological nation. Furthermore, students shun sciences particularly Physics when given an option and this especially applies to girls (Aduda, 2003). This implies that given a choice, a student would rather drop Physics in favour of other science subjects.

Improving the learning of Physics and achievement in it requires a lot of input from the teachers because the role of the teacher in the classroom is important. The teaching approach that a teacher adopts and the available materials he/she teaches with are factors that may affect students achievement (Mills, 1991). Therefore, the use of appropriate teaching equipment and teaching method is critical to the successful teaching and learning of Physics. Although, studies had been conducted examining different teaching methodology adopted in Physics class for example, Bello (2011) found out that using small group cooperative teaching method facilitated students' learning in Physics. This method also increased students' motivation to learn, also below average students' were found to improve on their achievements than in regular teaching method class. The cooperative concept mapping approach teaching method enhanced the teaching of secondary school science (Orora, Wachanga \& Keraro, 2005). Also, Kibett \& Kathuri (2005) found that students who were taught using project based learning out performed their counterparts in regular teaching approach. There are still much to be done in the area of effective utilization of available teaching equipment. Therefore, this study aimed at finding out the available and utilized Physics laboratory equipment and its effect on the students' achievements in Physics.

More often than not, unavailability or inadequacy of suitable teaching facilities is blamed for the poor performance among other factors such as the teacher competency, teaching methodology and the attitude of the students towards the subject. Using adequate and suitable laboratory equipment to teach Physics in secondary schools will help to improve the academic achievement of learners. The available research in literature does not indicate any research on the effectiveness of suitable Physics laboratory equipment (PLE) in senior secondary school Physics in Nigeria. This research study was therefore intended to fill this gap in the body of knowledge. The study provided empirical evidence on the utilization of suitable and available PLE and its influence on students' achievement in senior secondary school Physics.

\subsection{Objective of the Study}

The specific objectives of the study were to:

(i) investigate the availability of PLE for the teaching and learning of Physics in senior secondary schools in Nigeria;

(ii) determine the extent of utilizing the available PLE for the teaching and learning of Physics in senior secondary schools in Nigeria;

(iii) obtain the relationship between the utilization of PLE and the academic performance of students in Physics.

\subsection{Research Questions}

The following research questions were raised to guide the study:

(i) Are there PLE for the teaching of Physics in Nigeria Senior Secondary Schools?

(ii) Are the available PLE utilized by teachers in the teaching and learning process?

(iii) Does the utilization of PLE have any influence on the academic achievement of students? 


\section{Methodology}

This study employed the descriptive survey design.Forty five senior secondary schools comprising of twenty four public, fourteen private and seven federal/unity schools were randomly selected from the south western region of Nigeria. The sample for the study consisted of the Physics teacher(s) of each school and twenty senior secondary 2 (SS2) Physics studentsrandomly chosen from each school, making a total of fifty Physics teachers and nine hundred senior secondary twoPhysics students.

\subsection{Research Instruments}

Three instruments were used for the collection of data for this study. The first instrument was a 32-item self-designed validated and reliability ascertained questionnaire titled "Physics Laboratory Equipment Questionnaire" (PLEQ), with reliability $\mathrm{r}=0.72$; the second instrument was a checklist titled "Physics Laboratory Equipment Checklist" (PLEC) and the third instrument was "Physics Achievement Test (PAT). The questionnaire contains two sections. Section A contained general questions and statements to inquire general information about the school, the Physics teacher and practical activities that take place during Physics class; Section B contained statements that inquire about the teachers' views on the available PLE, the influence of using PLE on students' academic achievements in Physics and the relevance of the available PLE to the teaching of Physics. The checklist consisted of lists of the expected PLE on various aspects of Physics practicals. The lists were grouped into six major topics in Physics where practical work is required, the topics are: Mechanics, Heat and Energy, Current Electricity, Light and Optics, Waves and Sound, Magnetism. The available and the utilized PLE were indicated on the checklist.

The third instrument was Physics Achievement Test (PAT) which consisted of 25 structured multiple choice questions on Physics topics that were taught to the students in their last term class of SS2. This was drawn in order to know the relationship between the utilization of PLE with the academic achievement of the students.Each question has a maximum score of 4 making a total mark of 100 .

\subsection{Data Collection and Analysis}

Copies of the questionnaire were administered by the researcher to the Physics teachers and twenty students in each school. The checklist was used to cross check the available equipment in the laboratory of each school with the help of the Physics teacher and the laboratory attendant. The PAT was administered to the senior secondary two students, the researcher scored the test and generated quantitative data, which were analysed. All the data collected were edited and analyzed using descriptive statistics and percentages.

\section{Results}

The results of the analysis of the data obtained for each of the research questions are presented as follows:

Research question one: Are there PLE for the teaching of Physics in Nigeria Senior Secondary Schools?

Table 1: Percentage distribution of PLE available in senior secondary schools

\begin{tabular}{lllll}
\hline Type of Experiment & Private Schools & Public Schools & Federal Schools & Total \\
\hline Mechanics & 33.4 & 29.1 & 37.5 & 34.1 \\
Heat Energy & 36.4 & 21.6 & 42.0 & 16.4 \\
Current/Electricity & 33.7 & 31.9 & 34.4 & 25.0 \\
Light and Optics & 33.7 & 33.7 & 32.6 & 15.3 \\
Waves and Sound & 31.0 & 21.4 & 47.6 & 04.8 \\
Magnetism & 35.5 & 21.1 & 43.4 & 04.4 \\
Total & 34.0 & 28.6 & 37.4 & 100.0 \\
\hline
\end{tabular}

From table 1, it was observed that the available PLE varies for different types of school. The federal schools had the highest number of PLE in mechanics (37.5\%), heat energy (42.0\%), current/electricity (34.4\%), waves and sound $(47.6 \%)$, and magnetism (43.4\%), this is followed by the private schools, which have the same as public schools in light and optics (33.7\%), mechanics (33.4\%), heat energy (36.4\%), current electricity (33.7), waves and sound $(31.0 \%)$ and magnetism (35.5\%). The public schools had the least number of available PLE with the exception of 
light and optics and an appreciable number in current/electricity which is $31.9 \%$. Also, all the schools have the highest number of PLE in mechanics option (34.1\%), followed by current electricity $(25.0 \%)$ with the least being waves and sound (04.8\%) and magnetism (04.4). In the same vein, the overall result showed that federal schools (37.4\%) have the highest number of PLE followed by the private schools (34.0\%) and the public $(28.6 \%)$ having the least.

Research Questions Two: Are the available PLE utilized by teachers in the teaching and learning process?

Table 2: Percentage distribution of the utilization of PLE in senior secondary schools

\begin{tabular}{lllll}
\hline Type of Experiment & Private Schools & Public Schools & Federal Schools & Total \\
\hline Mechanics & 34.3 & 27.7 & 38.1 & 34.4 \\
Heat Energy & 37.5 & 22.7 & 39.8 & 15.0 \\
Current/Electricity & 33.3 & 31.0 & 35.7 & 26.7 \\
Light and Optics & 33.0 & 35.2 & 31.8 & 16.3 \\
Waves and Sound & 32.1 & 30.2 & 37.7 & 03.2 \\
Magnetism & 36.0 & 20.0 & 44.0 & 04.5 \\
Total & 34.3 & 28.8 & 36.9 & 100.0 \\
\hline
\end{tabular}

Table 2 showed that the frequency of utilization of PLE varies from experiment to experiment. It also differs for the types of school. The federal schools had the highest utilized capacity of PLE in all the experiment option except in light and optics. The federal schools have utilization capacity of $38.1 \%$ in mechanics, $39.8 \%$ in heat energy, $35.7 \%$ in current/electricity, $37.7 \%$ in waves and sound, and 44.0 in magnetism. The result further showed that private schools were ranked second in the usage of PLE for teaching learning process, while the public schools had the least utilization capacity with the exception in light and optics where the utilization capacity is $35.2 \%$ and the least percentage in magnetism (20.0\%). Overall usage of PLE for teaching/learning process revealed that there is highest usage of equipment in mechanics (34.4\%), this is followed by current/electricity (26.7\%), with waves and sound $(03.2 \%)$ and magnetism (04.5) having the least. Furthermore, the overall result showed that federal schools (36.9\%) have the highest capacity usage of PLE followed by the private schools $(34.3 \%)$ and the public schools $(28.8 \%)$ having the least.

Research Questions Three: Does the utilization of PLE have any influence on the academic achievement of students in Physics?

Table 3: Chi-square statistics showing the influence of utilization of PLE on the academic achievement of students in Physics

\begin{tabular}{cccc}
\hline & Value & Df & Asymptotic. Sig \\
\hline Chi-Square Calculated & 232.647 & 9 & 0.05 \\
Chi-Square Table & 16.919 & & 0.05 \\
\hline
\end{tabular}

Results shown in table 3 revealed that the calculated chi-square value $\left(\chi_{\text {cal. }}^{2}=232.64\right)$ is greater than the table chi-square $\left(\chi_{\text {tab. }}^{2}=16.919\right)$, this is an indication that there is significant relationship between the utilization of PLE and academic achievement of students in Physics, which revealed that utilization of PLE have influence on the academic achievements of students in Physics. 
Table 4: Statistical mean of the students' score in PAT for the different types of school

\begin{tabular}{cccc}
\hline Type of School & No & Mean $(\bar{X})$ & SD \\
\hline Private & 234 & 53.8 & 11.85 \\
Public & 291 & 50.8 & 12.32 \\
Federal & 117 & 67.6 & 10.25 \\
\hline
\end{tabular}

Table 4 showed that the students from the federal schools had the highest mean score of 67.6, this is followed by the private school students with public schools students having the least mean score. In similar manner, the federal school has the least standard deviation while the public school has the highest.

\section{Discussion}

In response to question one which sought to determine if there are PLE for the teaching of Physics in Nigeria senior secondary schools, the data showed that there are PLE for the teaching of Physics, but this varies with type of school in line with the ownership of the school. The result revealed that federal schools had the highest percentage of PLE for the teaching/learning process, this is followed by the private owned schools while the public schools had the least. This implies that more attention is given to federal schools (owned by federal government) than public schools (owned majorly by state government and community). This is due to the fact that adequate allocation is alloted to federal schools for the purchase of laboratory equipment than state owned schools. Proprietors of private schools most of the time improve on the standard of the school and would have had all the necessary laboratory equipment in place before getting approval for their schools. Also, parents prefer to take their wards to a better school that is fully equipped and that have a good academic package, therefore this stirs up competition among the schools and make them equip their laboratories better.

Furthermore, in response to question two which sought to determine if the available PLE are utilized by teachers in the teaching and learning process. The result showed that the PLE are being adequately utilized for teaching/learning process. This could be deduced from the percentage available and the percentage utilized. The utilization capacity also differs for the different types of school with federal schools having on the average the highest utilization capacity, this is followed by the private schools with the public schools having the least. This is in agreement with Lorton \&Walley (1979) who opined that learning experiences are richest when the environments which have physical laboratory equipments around them meet their needs through its adequacy and effective utilization.

Also, in response to question three which was to investigate the influence of utilization of PLE on the academic achievement of students. The result showed that there is significant relationship between effective utilization of PLE and the academic achievement of students (see table 3). It was further shown that students from schools with high percentage of available and well utilized PLE had the highest mean score, while those with the least overall percentage have the least mean score. This implies that the optimal availability and utilization of PLE is effective in the teaching/learning of Physics. This corroborates the findings of Olatunbosun (2008) who found that laboratory adequacy affect the performance of students. This is true as students tend to understand and recall what they see more than what they hear. Similarly, Zitoon \& Al-Zaubi (1986) concluded that the laboratory method is more effective compared with the traditional method in developing the scientific skills, also, Odubunmi \& Balogun (1991) found that low achieving students using the laboratory method performed better than their counterparts who received the lecture method, while Khawla \& Abdul (1999) found that the total number of secondary science laboratory experiments observed by the students whilst at school do have higher effect on their academic achievement in the laboratory science courses. Lunetta, Hofstein \& Giddings (1981) on the other hand reported that laboratory instruction may play an important part in the achievement of some science teaching goals, but not all the stated goals of science education, as many teachers have not incorporated laboratory goals into their instruction and evaluation systems. On the contrary Thijs \& Bosch (1995) found that there was no significant differences in achievement between the laboratory and the demonstration methods and suggested that the extent to which laboratory instruction, experiments, and textbook are congruent with the expected objectives of teaching sciences should be investigated. This implies that Physics laboratory work helps to simplify abstractness aspect of Physics thereby increasing the students' performance in academic environment. Also, it caters for individual differences, which encourages sharing of ideas and team work. Therefore, there is strong positive significant relationship between laboratory equipments and 
academic performance.

\section{Conclusion}

This study has established the fact that availability and effective utilization of PLE has positive influence on the academic achievement of students in Physics. Poor state of performance as well as mass failure of Physics in senior secondary schools is linked to the level of availability and utilization of PLE in Nigerian senior secondary schools. It further revealed that available and utilized PLE depend largely on the ownership of the schools. The study concluded that science laboratory is a critical variable in determining the quality of output from secondary schools. The findings showed that science laboratory had significant relationship with quality of output from secondary schools. The following recommendations are made based on the findings of this study:

$>$ The secondary schools should be provided with standard laboratory (especially the state owned public schools) in which improvised and other concrete materials such as models and specimens could be stored for the purpose of science teaching.

$>$ High priority should be placed on good management techniques of the science laboratories in order to appraise the technology of science instruction in the schools which enables us to develop within the limits of our human and material resources, a system that enhances understanding, thinking, production and problem solving.

> Inspections should be routinely carried out on schools' laboratories and worn out equipment replaced with new ones.

$>$ Teachers should be taught on how to improvise on certain laboratory materials as well as help the schools to discover ways of improvising the laboratory equipment from locally and available materials.

It is therefore recommended that the study be carried out on other science subjects such as biology, chemistry and agriculture in order to know the problems associated with teaching the subjects with the view to improving the students' academic achievement.

\section{References}

Aduda, D. (2003). Meeting gives Tips on How to Improve Science Subjects. The Daily Nation, Nairobi, Kenya: Nation Media group Ltd (p.15).

Ali, A. (1990). Review of research studies in science education. Review of Education Journal, 1(10), 161-165.

Alsop, S., \& Hicks, K. (2001).Teaching Science:A Handbook for Primary and Secondary School teaching. Glasgow: Bell \& Bain Ltd..

Bello, T. O. (2011). Effect of group instructional strategy on students' performance in selected Physics concepts. The African Sympossium: An on-line Journal of African Educational Research Network, 11(1), 71-79

Changeiywo, J.M. (2000). Students Image of Science in Kenya: A Comparison by Gender difference of Schooling and Regional Disparities. Unpublished $\mathrm{PhD}$ Thesis, Egerton University Kenya.

Ho, F. F., \& Boo, H. K. (2007). Cooperative learning: Exploring its effectiveness in the Physics classroom. Asia Pacific Forum on Science Learning and Teaching, 8(2). http//dx.doi.org/ied.edu.hk/apfslt

Hofstein, A. (2004). The laboratory in chemistry education: thirty years of experience with developments, implementation and evaluation. Chemistry Education Research and Practice, 5, 247-264. http://dx.doi.org/10.1039/b4rp90027h

Hofstein, A., \& Lunetta, V.N. (2004). The laboratory in science education: Foundation for the $21^{\text {st }}$ Century. Science Education, 88, 28 - 54. http://dx.doi.org/10.1002/sce.10106

Khawla, S. S., \& Abdul, H. M. E. (1999). The relationship between school laboratory experiments and academic achievement of Palestinian students in introductory university science courses. Research in Post-Compulsory Education, 4,1 .

Kibett, J.K., \& Kathuri, N. J. (2005). Effects of projected-based learning on students'performance in secondary school Agriculture. Zimbabwe Journal of Educational Research, 17(1), 30-38.

Lorton, V., \& Walley, B. (1979). International association for the evaluation of educational achievement in seventeen 
centuries - A preliminary report. Oxford Pergamon. Pp 25-26.

Lunetta, V.N., Hofstein, A., \& Giddings, G. (1981). Evaluating science laboratory skills. The Science Teacher, January, 22-25.

Mills, H. R. (1991). Teaching and training: A handbook for instructors (3rd ed). London: Macmillan Publishers.

Minishi, O., Muni, E., Okumu, O., Mutai P., Mwangasha, G., Omolo, H., \& Munyeke, F. (2004). Secondary Physics form one(3rd ed.). Nairobi: Kenya Literature Bureau.

Nneji, N. C. (1998). Students' teachers and examiners perception of difficult topics in applied electricity and factors responsible for the difficult level. Journal of the Science Teachers Association of Nigeria, 6, 56-61.

Odubunmi, O., \& Balogun, T.A. (1991). The effect of laboratory and lecture teaching methods on cognitive achievement in integrated science. Journal of Research in Science Teaching, 3, 213-224. http://dx.doi.org/10.1002/tea.3660280303

Ogunleye, A. O. (2000). Towards the optimal utilization and management of resources for effective teaching and learning of Physics in schools. Proceedings of the 41st annual conference of the Science Teachers Association of Nigeria, 215-220.

Okebukola, P. A. (1997). Some factors in students' under-achievement in senior secondary school Biology. Journal of Science Education, 2(2), 9-12.

Olatunbosun, M. (2008). Student teacher and school environment factors as determinant of achievement in senior secondary school Chemistry in Oyo State, Nigeria. The Journal of International Social Research, 1(2), 56-60

Orora, W., Wachanga, S. W., \& Keraro, F. N. (2005). Effects of concept mapping teaching approach on secondary school students' achievement in Biology in Gucha District Kenya. Zimbambwe Journal of Educational Research, 17(1), 1-18.

Thijs, G.D., \& Bosch, G.M. (1995). Cognitive effect of experiments focusing on students' pre-conceptions of force: a comparison of demonstrations and small-group practical. International Journal of Science Education, 3, 311-323. http://dx.doi.org/10.1080/0950069950170304

Umeh, M. O. (2002). Reducing teachers' instructional difficulties in some content areas of some senior secondary school Biology curriculum for sustainable development. Proceedings of the 43rd annual conference of the Science Teachers Association of Nigeria.

Vaidya, N. (2003). Science Teaching for 21st Centur. New Delhi: Deep \& Deep Publication PVT. Ltd.

Wenham, E.J., Dorlin, G.W., Snell, J.A. .N., \& Taylor, B. (1984). Physics: Concepts and Models (2nd ed). Addison Wesley.

Zhaoyao, M. (2002). Physics Education for the 21st Century: Avoiding a Crisis. Physics Education, 37(1), 18-24.

Zitoon, A., \& Al-Zaubi, T. (1986). The effect of using laboratory on developing science thinking skills of 11th grade students in Jordan. Journal of Education, 9, 94-117. 